\title{
A Rapid and Eco-Friendly Method for Determination of Hydrolysable Tannins and Its Application to Honey Samples
}

\author{
Tiago Augusto Catelani ${ }^{1}$ Dayana Borges Bittar ${ }^{1} \cdot$ Leonardo Pezza $^{1}$. \\ Helena Redigolo Pezza ${ }^{1}$
}

Received: 26 October 2015 / Accepted: 17 February 2016 / Published online: 23 February 2016

(C) Springer Science+Business Media New York 2016

\begin{abstract}
This paper describes the development of a rapid and clean method for the determination of hydrolysable tannins in honey samples, focusing on an easy and green sample pretreatment and low generation of waste. The proposed method is based on the reaction between $\mathrm{KIO}_{3}$ and hydrolysable tannin compounds in acetate buffer medium ( $\mathrm{pH} 4.75)$, with formation of a colored product measured at $525 \mathrm{~nm}$. The analytical conditions were optimized using experimental design (central composite design). The linear range obtained was $40.0-740 \mathrm{mg} \mathrm{L}^{-1}(r=0.998)$, and the detection (LOD) and quantification (LOQ) limits were 12.2 and $40.8 \mathrm{mg} \mathrm{L}^{-1}$, respectively. Acetate buffer was used to ensure formation of the colored product obtained by reaction between the chromogenic reagent and the analyte. The method showed good results when applied to honey samples, with recoveries in the range of 78.3$96.1 \%$, and the use of diffuse reflectance spectroscopy coupled with spot test analysis provided low reagent consumption and minimized waste generation. The results obtained with the proposed method were confirmed by a spectrophotometric method.
\end{abstract}

Keywords Honey · Hydrolysable tannin · Diffuse reflectance spectroscopy $\cdot$ Eco-friendly method

\section{Helena Redigolo Pezza}

hrpezza@iq.unesp.br

1 Instituto de Química, Universidade Estadual Paulista "Julio de Mesquita Filho", UNESP, R. Prof. Francisco Degni 55, P.O. Box 355, 14800-900 Araraquara, SP, Brazil

\section{Introduction}

Polyphenols are organic compounds that are widely found in plants and some foods. The production of honey from pollen derived from diverse flora results in the inclusion of polyphenolic compounds, particularly tannins, in the honey matrix.

Honey is a sweet product of animal origin, produced by bees as a food source from the nectar of plants, and its characterization contributes to ensuring a high-quality product and safeguarding the health of consumers (Uthurry et al. 2011; Codex 2001). A growing number of studies provide evidence of the importance of the antioxidant capacity of honey for therapeutic purposes (Gorjanovic et al. 2013; Gheldof et al. 2002; Ciappini and Stoppani 2014; Eterafi-Oskouei and Najafi 2013). Honey is consumed in large quantities worldwide, and in Brazil, imports in January 2015 were around $3.76 \times 10^{4} \mathrm{~kg}$ of common honey and $9.20 \times 10^{5} \mathrm{~kg}$ of organic honey (National Honey Report 2015).

Tannins are high-molecular-weight polyphenolic compounds found in two principal classes, hydrolysable and condensed tannins. Particular features of these compounds are their astringency and high antioxidant capacity (MuellerHarvey 2001). These structures include water-soluble phenolic compounds and have high molecular weights of between 500 and $3000 \mathrm{Da}$ (Chung et al. 1998).

Hydrolysable tannins contain either gallotannins or ellagitannins. The hydrolysis of gallotannins yields glucose and gallic acids, while ellagitannins contain hydroxydiphenoyl residues that produce ellagic acid after hydrolysis (Chung et al. 1998; Romani et al. 2006). Condensed tannins, otherwise known as proanthocyanidins, are compounds consisting of oligomers and polymers of flavan-3-ol units, usually linked via C4-C6 or C4-C8 bonds (Romani et al. 2006). 
Tannins are present in the matrix of honey as part of its natural composition, rather than due to external contamination. Bees collect the nectar of plants, and the tannins present in the nectar are transferred to the honey during its production (Uthurry et al. 2011).

The antioxidant capacity of tannin compounds present in foods, including the gallic and ellagic acids of honey, is highly important in terms of human health (Escuredo et al. 2013). Studies of the biological action of these compounds have revealed significant activity against certain microorganisms (Scalbert 1991) as well as carcinogenic and hepatotoxic substances (Chung et al. 1998). Tannins exhibit antiinflammatory and healing action and can inhibit HIV reverse transcriptase (Kilkuskie et al. 1992; Khanbabaee and Ree 2001). The presence of tannins in various natural matrices can show seasonality. Salminen et al. (2001) observed seasonal variation of hydrolysable tannins in leaves of Betula pubescens. Many tannins can act as scavengers of the free radicals that are associated with degenerative diseases such as cancer, multiple sclerosis, and atherosclerosis, with the tannins interacting with the active oxygen to form stable radicals.

Few analytical methods for the determination of hydrolysable tannins in honey have been reported in the literature, which highlights the importance of the study of hydrolysable tannins presented in this work, since honey is a product that is very widely consumed (Uthurry et al. 2011). The determination of tannins in complex matrices such as honey usually requires laborious procedures and/or extensive cleanup processes, and recoveries can be low. For matrices such as water, tea, and fruits, techniques used have included highperformance liquid chromatography (HPLC) (Ahmed et al. 2014; Silva et al. 2013; Xie et al. 2012), HPLC and capillary electrophoresis (Juang et al. 2004), and HPLC coupled with mass spectrometry (Campillo et al. 2015; Zywicki et al. 2002). The difficulty in analyzing hydrolysable tannins, compared to condensed tannins, has led to the study of these compounds being ignored. Mixtures of hydrolysable tannins have been analyzed using general tannin assays, such as precipitation with proteins or metals, and by colorimetric determination of total phenols (Mueller-Harvey 2001).

The development of new analytical methods is one of the most important goals of Green Chemistry. These methods aim to reduce or eliminate the use of hazardous substances and organic solvents, among other improvements, and are gaining ground in all aspects of chemistry (Keith et al. 2007; Anastas 1999; de La Guardia and Garrigues 2011). The fact that a new methodology is environmentally friendly is as important a factor as the analytical features of the method (Anastas 1999). Diffuse reflectance spectroscopy coupled with spot tests is considered a green analytical technique because it uses very small quantities of reagent and no organic solvents, reducing costs and producing minimal amounts of waste products. The technique offers speed and simplicity, while protecting human health and the environment. An important feature of the diffuse reflectance technique is that it can be performed using portable equipment, with filter paper providing a good surface for the spot test (Dias et al. 2006). Other methodologies using diffuse reflectance Fourier transform infrared spectroscopy have been reported in the literature (Pappas et al. 2015; Kyraleou et al. 2015).

Hydrolysable tannins react with potassium iodate $\left(\mathrm{KIO}_{3}\right)$ to produce a purple-colored product (Willis and Allen 1998). The reaction was first described by Haslam (1965), although its application in analytical determinations was subsequently reported by Bate-Smith (1977). The method proposed here is based on the reaction between hydrolysable tannins and potassium iodate in a buffered medium, with the reaction product being measured at $\lambda_{\max }=525 \mathrm{~nm}$. Experimental design was used to find the best conditions for determination of the analyte in honey samples.

The aim of the present work was therefore to develop a rapid, simple, and environmentally friendly method for the determination of hydrolysable tannins (Fig. 1) in honey, using a diffuse reflectance spectroscopy technique combined with spot tests, without any need for elaborate pretreatment of the honey samples.

\section{Experimental Section}

\section{Apparatus}

The diffuse reflectance spectroscopy measurements employed a handheld integrating sphere (ISP-REF, Ocean Optics, Dunedin, USA) connected to a fiber optic mini-spectrometer (USB 2000, Ocean Optics). Spectral acquisition was carried out using SpectraSuite software (Ocean Optics).

\section{Reagents and Solutions}

Ultrapure water (18 M $\Omega$ cm; Milli-Q System, Millipore) was used to prepare the solutions. Qualitative filter paper (Whatman no. 1) was used as the solid platform for the reaction. Potassium iodate (purchased from Mallinckrodt) was used as the chromogenic reagent, with an aqueous stock solution prepared at a concentration of $3.00 \times 10^{4} \mathrm{mg} \mathrm{L}^{-1}$ for the development of the central composite design. After optimization of the conditions, a solution of $\mathrm{KIO}_{3}$ at a concentration of $3.1 \times 10^{4} \mathrm{mg} \mathrm{L}^{-1}$ was prepared and used for the subsequent experiments, as indicated by the central composite design. Acetate buffer solution was prepared using a mixture of sodium acetate $\left(0.1 \mathrm{~mol} \mathrm{~L}^{-1}\right)$ and acetic acid $\left(0.1 \mathrm{~mol} \mathrm{~L}^{-1}\right)$, both purchased from Sigma-Aldrich. Tannic acid (Sigma-Aldrich) was used as the standard, with a stock solution prepared at a concentration of $1000 \mathrm{mg} \mathrm{L}^{-1}$ in an aqueous medium containing $3 \mathrm{~mL}$ of ethanol. Working standard solutions in the range 
Fig. 1 a Chemical structures of precursor molecules of the gallotannins (gallic acid) and ellagitannins (ellagic acid) and $\mathbf{b}$ chemical structures of gallotannins and ellagitannins

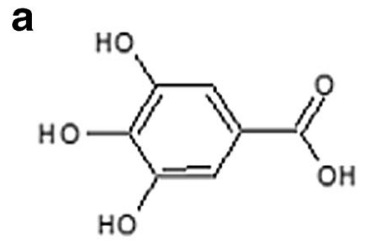

Gallic Acid<smiles>O=c1oc2c(O)c(O)cc3c(=O)oc4c(O)c(O)cc1c4c23</smiles>

Ellagic Acid
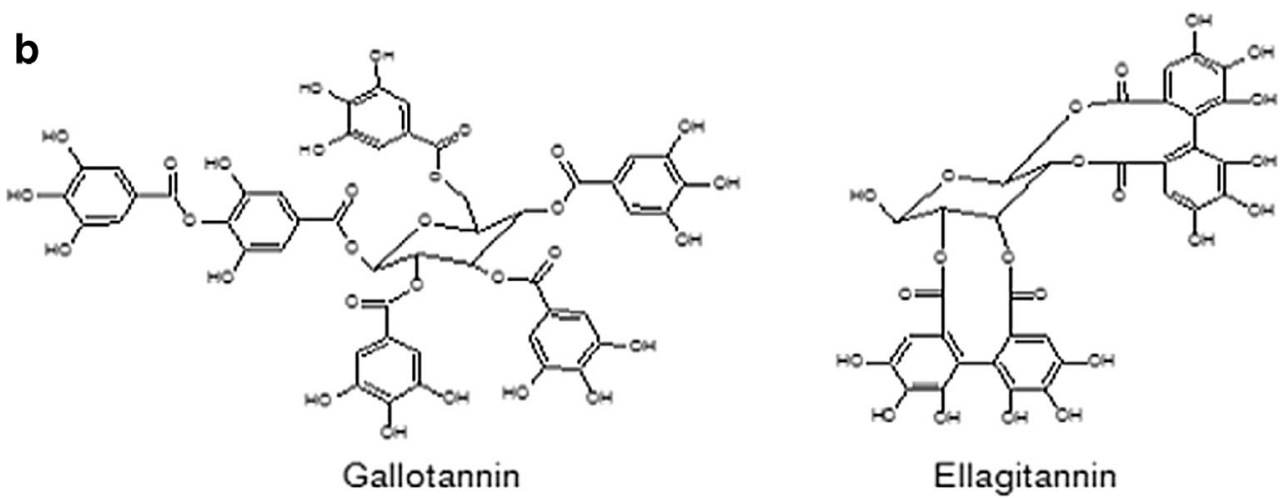

of 40.0-740.0 $\mathrm{mg} \mathrm{L}^{-1}$ were prepared by suitable dilution of the stock solution.

\section{Honey Samples}

Eight samples of orange and eucalyptus flower honey were purchased from different outlets in the municipalities of Araraquara and Matão (São Paulo State) and Cambé (Paraná State) and were used to evaluate the performance of the proposed method.

\section{Sample Preparation}

A portion $(5.0 \mathrm{~g})$ of the sample was solubilized in deionized water, with the aid of a magnetic stirrer, and transferred to a $25-\mathrm{mL}$ flask. The solution was filtered through a $0.45-\mu \mathrm{m}$ PVDF membrane (Millex-HV, Millipore), followed by washing of the membrane with two portions ( $7 \mathrm{~mL}$ each) of ethanol:water solution $(50 \%, v / v)$ in order to ensure complete removal of the analyte. Three different ethanol:water ratios were tested for the washing process $(30: 70,50: 50$, and 70:30), and the best results were obtained with the 50:50 mixture. The washing solutions were transferred to the $25-\mathrm{mL}$ volumetric flask, and the volume was completed with the ethanol:water solution.

\section{Procedure for the Spot Test Reaction}

A study of the influence of the volumes and the order of addition of the chromogenic reagent, tannic acid standard solution, and acetate buffer solution was performed in order to obtain the best absorbance values. The results obtained are shown in the "Results and Discussion" section.

\section{Experimental Design}

Evaluation of all the parameters involved in the method was performed using experimental design methodology. A multivariate analysis was applied in order to optimize the following selected variables: $\mathrm{KIO}_{3}$ concentration and $\mathrm{pH}$ of the buffer solution. The statistical analyses employed the Minitab 16 and Statistica 8.0 software packages.

\section{Analytical Curves}

After optimization of the variables, tannic acid standard solutions $(40,100,200,300,400,500,600$, and $740 \mathrm{mg} \mathrm{L}{ }^{-1}$ ) were spotted onto filter papers (Whatman no. 1), in triplicate, followed by addition of the buffer solution and the chromogenic reagent solution (in that order). The absorbance of the colored product was measured at $525 \mathrm{~nm}$ after $20 \mathrm{~min}$ of reaction.

\section{Study of Interferences}

Interferences were evaluated by studying the behavior of the reaction in the presence of the major compounds commonly present in honey (glucose, fructose, and hydroxymethylfurfural). 
Concentrations 10 times greater than that of tannic acid were evaluated under the same conditions described for the samples.

\section{Standard Additions}

The proposed method was validated using standard additions and investigation of possible matrix effects associated with the honey. Samples were spiked with tannic acid at 50, 100, 150, 200 , and $250 \%$ of the initial concentration of the spiked sample and were then analyzed by the proposed method.

\section{Comparative Method}

The honey samples were also analyzed by a comparative method, as described by Nunes et al. (2009). This was based on reaction of the tannins with iron(III) chloride in a medium containing sodium dodecyl sulfate (SDS), triethanolamine, and isopropanol. The colored product formed by reaction between $\mathrm{FeCl}_{3}$ and the tannins was measured spectrophotometrically at $715 \mathrm{~nm}$.

\section{Results and Discussion}

The proposed method is based on the reaction between hydrolysable tannins and $\mathrm{KIO}_{3}$ as the chromogenic reagent. $\mathrm{KIO}_{3}$ reacts with hydrolysable tannins to produce a transient purplecolored product that can be measured at $525 \mathrm{~nm}$. Evaluation of the stability of this transient product revealed that the color reached maximum absorbance after 20 min of reaction, with this value being maintained for $15 \mathrm{~min}$, after which the color started to disappear, with formation of a yellow product. The formation of this yellow degradation product has been described previously (Bossu et al. 2006).

In preliminary experiments, the effects of the buffer medium and the order of addition of the solutions to the filter paper were evaluated. Different buffer media were used in order to identify the $\mathrm{pH}$ at which the colored product was formed by reaction between the chromogenic reagent and hydrolysable tannins. The influence of the buffer medium was evaluated using the following three different buffers: $\mathrm{H}_{3} \mathrm{PO}_{4} / \mathrm{H}_{2} \mathrm{PO}_{4}{ }^{-}$(pH 2.14), $\mathrm{H}_{2} \mathrm{PO}_{4}^{-} / \mathrm{HPO}_{4}{ }^{2-}$ (pH 7.00), and acetic acid/sodium acetate $(\mathrm{pH} 4.75)$. The results showed that at $\mathrm{pH} 2.14$ and $\mathrm{pH} 7.00$, the transient purple-colored product was not obtained, with formation of yellow and brown products, respectively. Formation of the transient colored product only occurred in the presence of the acetate/acetic acid buffer (pH 4.75). It can be seen that the reaction was strongly influenced by the $\mathrm{pH}$ and that formation of the transient purple product occurred at $\mathrm{pH} 4.75$.

The influence of the order of addition of the analyte, chromogenic reagent, and buffer solutions to the filter paper was also evaluated. The results of these tests showed that the best conditions for the reaction were provided by addition of the analyte, followed by the buffer solution, and lastly, addition of the chromogenic reagent.

In the sample filtration step, the analyte was completely retained on the $0.45-\mu \mathrm{m}$ PVDF micropore membrane. Preliminary tests performed with tannic acid standard solution demonstrated the need for two successive steps of washing the membrane with portions of ethanol:water solution $(50 \%, v / v)$ in order to completely remove the analyte. A third wash was performed in order to confirm total elution of the analyte, which indicated that only two washes were required. Figure 2 shows the spectra obtained after reaction of the $\mathrm{KIO}_{3}$ chromogenic reagent with the first, second, and third washing solutions in $\mathrm{pH} 4.75$ buffer medium (where $A$ is the spectrum for a tannic acid standard solution and $B$ is the spectrum for a sample solution).

\section{Optimization of Variables}

\section{Central Composite Design}

Multivariate analysis was used to optimize the variables, employing a central composite design to identify the optimal conditions that provided the best analytical results. A response surface analysis was applied, using the selected variables, $\mathrm{KIO}_{3}$ concentrations in the range from $1.50 \times 10^{4}$ to $3.00 \times 10^{4} \mathrm{mg} \mathrm{L}^{-1}$ and buffer $\mathrm{pH}$ from $\mathrm{pH} 2.14$ to $\mathrm{pH} 6.50$.

Table 1 presents the central composite design matrix, considering different combination of the factors. From the preliminary experiments, it was possible to select lower $(-1)$ and upper $(+1)$ levels for the variables, resulting in 13 experiments (carried out in triplicate) for analysis of the influence and significance of the factors. In all experiments, the concentration of the tannic acid standard solution was kept constant at $700 \mathrm{mg} \mathrm{L}^{-1}$.

From the data shown in Table 1, a central composite design graph was constructed (Fig. 3) to identify the optimal conditions for the analysis, considering the absorbance values obtained for each combination of variables. A statistically significant quadratic model, accounting for $89.0 \%$ of the variance, was fitted to the data, describing the relation between the maximum absorbance and the optimal experimental conditions. The quadratic regression model is given by Eq. (1).

$$
\begin{aligned}
Z= & -0.0866+0.0053^{*} x-0.0000835^{*} x^{2} \\
& +0.130 * y-0.0171^{*} y^{2}+0.000865 x y
\end{aligned}
$$

where $Z$ is the response factor corresponding to the absorbance value and $x$ and $y$ are the $\mathrm{KIO}_{3}$ concentration and buffer $\mathrm{pH}$, respectively. From the surface obtained, the critical values found for the $\mathrm{KIO}_{3}$ concentration and the buffer $\mathrm{pH}$ were $3.10 \times 10^{4} \mathrm{mg} \mathrm{L}^{-1}$ and $\mathrm{pH} 4.75$ (acetate buffer), respectively. 
a

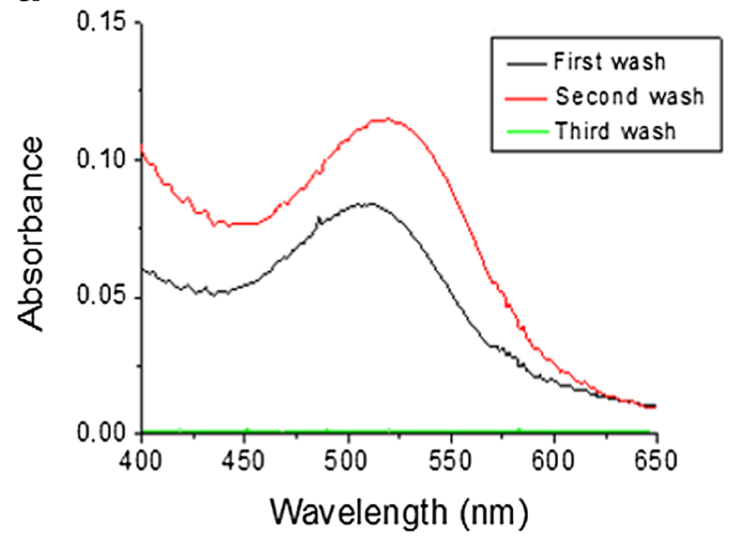

b

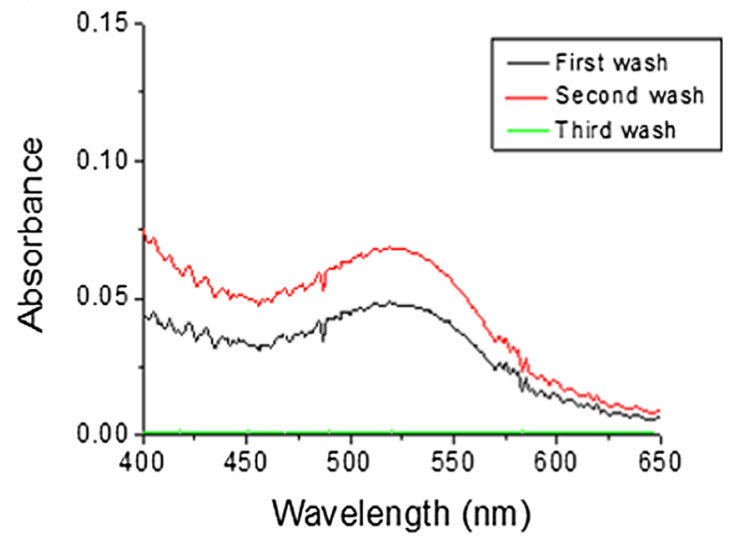

Fig. 2 a Spectrum obtained for the reaction between tannic acid standard solution $\left(C_{\text {tannic acid }}=700.0 \mathrm{mg} \mathrm{L}^{-1}\right)$ and $\mathrm{KIO}_{3}$ after washing of the $0.45-\mu \mathrm{m}$ membrane and $\mathbf{b}$ spectrum obtained for the reaction between a honey sample and $\mathrm{KIO}_{3}$ after washing of the $0.45-\mu \mathrm{m}$ membrane

\section{Analytical Features}

The proposed method was evaluated using the following parameters: linear range, precision, accuracy, limit of detection (LOD), and limit of quantification (LOQ).

After optimization of the variables and obtaining the best analytical conditions, a linear analytical curve was constructed using concentrations of tannic acid in the range of $40-$ $740 \mathrm{mg} \mathrm{L}^{-1}$. The repeatability was evaluated using intraand inter-day measurements at two concentrations; for a $140 \mathrm{mg} \mathrm{L}^{-1}$ standard solution of tannic acid, the \%RSD values were 1.94 and 2.34 , respectively, while for a concentration of $640 \mathrm{mg} \mathrm{L}^{-1}$, the values were 1.16 and 3.93 , respectively. These results were considered acceptable and showed that the proposed method could be used for the analysis of

Table 1 Central composite design matrix

\begin{tabular}{lll}
\hline Experiments & \multicolumn{2}{l}{ Factors $^{\mathrm{a}}$} \\
\cline { 2 - 3 } & $\mathrm{KIO}_{3}$ concentration $\left(\mathrm{mg} \mathrm{L}^{-1}\right)$ & $\mathrm{pH}$ \\
\hline 1 & $1.50 \times 10^{4}(-1)$ & $2.14(-1)$ \\
2 & $3.00 \times 10^{4}(+1)$ & $2.14(-1)$ \\
3 & $1.50 \times 10^{4}(-1)$ & $6.50(+1)$ \\
4 & $3.00 \times 10^{4}(+1)$ & $6.50(+1)$ \\
5 & $1.20 \times 10^{4}(-\sqrt{ } 2)$ & $2.14(-1)$ \\
6 & $3.30 \times 10^{4}(\sqrt{ } 2)$ & $2.14(-1)$ \\
7 & $1.50 \times 10^{4}(-1)$ & $1.00(-\sqrt{ } 2)$ \\
8 & $1.50 \times 10^{4}(-1)$ & $7.00(\sqrt{ } 2)$ \\
9 & $2.25 \times 10^{4}(0)$ & $4.75(0)$ \\
10 & $2.25 \times 10^{4}(0)$ & $4.75(0)$ \\
11 & $2.25 \times 10^{4}(0)$ & $4.75(0)$ \\
12 & $2.25 \times 10^{4}(0)$ & $4.75(0)$ \\
13 & $2.25 \times 10^{4}(0)$ & $4.75(0)$ \\
\hline
\end{tabular}

${ }^{\mathrm{a}}$ The coded values are in parentheses hydrolysable tannins in honey samples. Table 2 presents the analytical parameters of the proposed method.

The LOD and LOQ values were determined according to IUPAC recommendations (Long and Winefordner 1983), using the expressions $3 \times(s / b)$ and $10 \times(s / b)$, respectively, where $s$ is the standard deviation of measurements of the blanks $(n=10)$ and $b$ is the slope of the linear range. The calculated LOD and LOQ values were 12.2 and $40.8 \mathrm{mg} \mathrm{L}^{-1}$, respectively.

\section{Study of Interferences}

The study of potential interfering compounds was performed considering the typical composition of honey samples, with evaluation of the effects of hydroxymethylfurfural (HMF), glucose, and fructose. No interferences in the proposed method were observed for the interferent concentrations tested.

\section{Analysis and Recovery Using Honey Samples}

The hydrolysable tannin contents were quantified for eight samples of honey. Table 3 presents the results obtained for honey samples from different origins and flowers, using the proposed and comparative methods. It can be seen that the eucalyptus honey samples had higher contents of hydrolysable tannins, compared to the orange honey samples. This could have been due to the different floral origins, as well as other factors such as the type of soil, source of the nectar, geographic origin, and seasonal climatic variations (A1Mamary et al. 2002). It can also be noted that the samples from Paraná State showed higher concentrations of these compounds, compared to samples from São Paulo state, which could be attributed to different seasonal and environmental conditions.

The production of honey is carried out using the nectar of plants. Several components (water, organic acids, carbohydrates, pollen, and wax) are due to maturation of the matrix, 

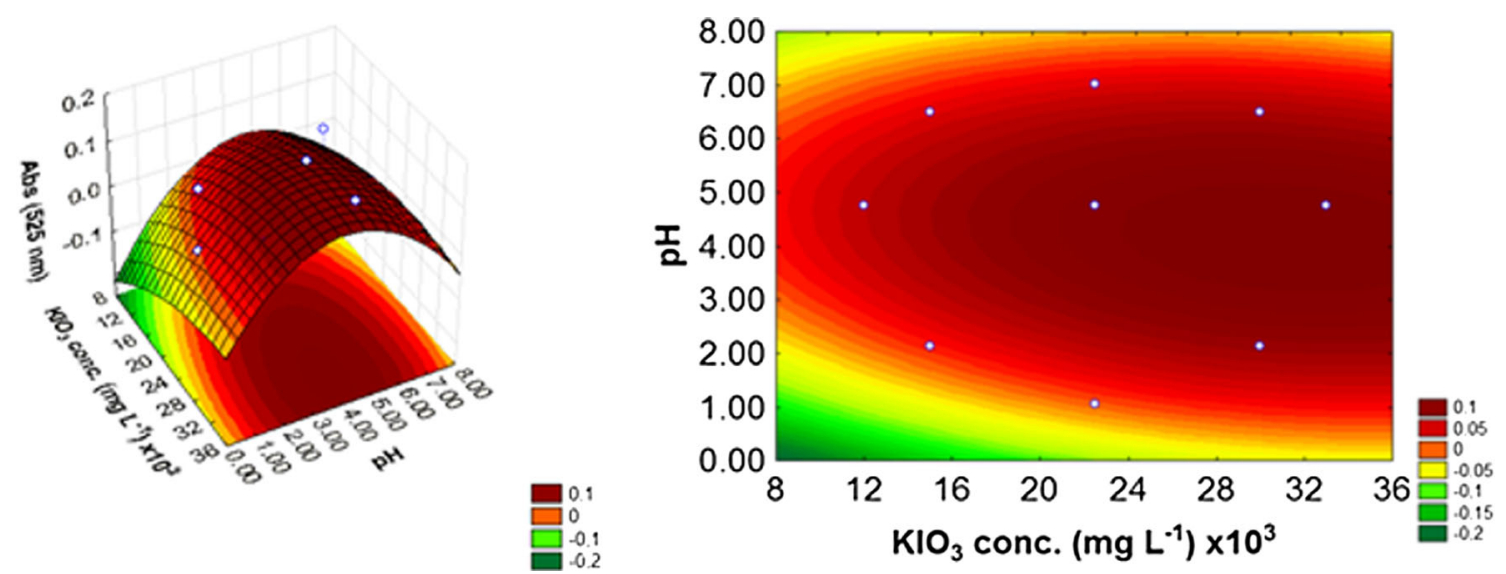

Fig. 3 Central composite design response surface and its projection, obtained for absorbance values as a function of $\mathrm{KIO}_{3}$ concentration and $\mathrm{pH}$

while others are added by the bees and can be derived from plants of different regions. In the case of honey derived from the same flora, there can be variations due to seasonal climatic fluctuations or different geographic origins. The proportions of the components of honey largely depend on the source of the nectar, and for the same flora, the mineral content can vary from $0.04 \%$ for pale honey to $0.2 \%$ for dark honey, depending on the type of soil in which the plant grows (Anklam 1998).

The data given in Table 3 show that there was consistency between the concentrations found using the proposed and comparative methods. Application of the paired $t$ test resulted in value below the tabulated value, indicating that there was no significant difference between the methods.

The accuracy of the proposed method was evaluated by determining the recovery of known concentrations of tannic acid spiked into honey samples, taking into account the initial concentrations naturally present. Two samples (one from orange flora and one from eucalyptus flora) were selected for the study. Spiking was performed at concentrations 50, 100, 150, 200 , and $250 \%$ higher than already present in the honey. Table 4 shows the recovery results for the proposed method, from which it could be concluded that the new technique provided good accuracy and an absence of matrix effects.

Table 2 Figures of merit of the proposed method

\begin{tabular}{ll}
\hline Parameters & Values \\
\hline Linear range & $40.0-740.0 \mathrm{mg} \mathrm{L}^{-1}$ \\
Coefficient of correlation $(r)$ & 0.998 \\
Slope & $1.70 \times 10^{-4}$ \\
Limit of detection $^{\mathrm{a}}$ & $12.2 \mathrm{mg} \mathrm{L}^{-1}$ \\
Limit of quantification $_{\text {Wavelength }}$ & $40.8 \mathrm{mg} \mathrm{L}$ \\
Calibration curve & $525 \mathrm{~nm}$ \\
\hline
\end{tabular}

${ }^{\mathrm{a}}$ Standard deviation of the blank $(\mathrm{s})=6.94 \times 10^{-4}$
The use of the proposed method to determine hydrolysable tannins offers several advantages, compared to the analytical methods described in the literature, which require large volumes of organic solvents such as acetonitrile, diethyl ether, formic acid, methanol, and dichloromethane (Ahmed et al. 2014; Xie et al. 2012), generating chemical wastes that contribute to environmental pollution. The earlier methods are also generally more time consuming. The proposed method is simple, fast, low cost, and sufficiently sensitive for determination of the target analytes in honey samples. Furthermore, the sample treatment only requires ethanol, which is a renewable organic solvent. Other important features are that there is no need for any elaborate sample pretreatment or cleanup steps, reagent and sample consumption is low, and waste generation is minimal (about $0.381 \mathrm{mg}$ per analysis) when compared to other methods described in the literature.

Table 3 Quantification of hydrolysable tannins in honey samples by the proposed and comparative methods

\begin{tabular}{lll}
\hline Samples & Proposed method $\left(\mathrm{mg} \mathrm{kg}^{-1}\right)$ & Comparative method $\left(\mathrm{mg} \mathrm{kg}^{-1}\right)$ \\
\hline $1^{\mathrm{a}, \mathrm{e}}$ & $519.3 \pm 31.7$ & $516.8 \pm 10.7$ \\
$2^{\mathrm{b}, \mathrm{c}}$ & $290.5 \pm 11.7$ & $294.5 \pm 10.7$ \\
$3^{\mathrm{b}, \mathrm{d}}$ & $327.6 \pm 10.7$ & $327.7 \pm 10.9$ \\
$4^{\mathrm{b}, \mathrm{c}}$ & $321.4 \pm 10.7$ & $322.1 \pm 10.7$ \\
$5^{\mathrm{a}, \mathrm{d}}$ & $383.3 \pm 11.5$ & $380.9 \pm 10.7$ \\
$6^{\mathrm{a}, \mathrm{c}}$ & $445.1 \pm 0.0$ & $448.4 \pm 0.0$ \\
$7^{\mathrm{b}, \mathrm{e}}$ & $340.4 \pm 21.5$ & $337.3 \pm 21.5$ \\
$8^{\mathrm{a}, \mathrm{d}}$ & $383.8 \pm 10.7$ & $381.1 \pm 11.4$ \\
\hline
\end{tabular}

Student's $t$ test calculated value $=0.326$ and tabulated value $=2.365$ (95\% confidence level)

${ }^{a}$ Eucalyptus honey samples

${ }^{\mathrm{b}}$ Orange honey samples

${ }^{\mathrm{c}}$ Sample from Araraquara/SP Municipality

${ }^{\mathrm{d}}$ Sample from Matão/SP Municipality

${ }^{\text {e }}$ Sample from Cambé/PR Municipality 
Table 4 Recovery values obtained using the proposed method.

\begin{tabular}{llll}
\hline Sample & $\begin{array}{l}\text { Added value } \\
\left(\mathrm{mg} \mathrm{kg}^{-1}\right)\end{array}$ & $\begin{array}{l}\text { Found value } \\
\left(\mathrm{mg} \mathrm{kg}^{-1}\right)\end{array}$ & Recovery (\%) \\
\hline $\begin{array}{llll}\text { Eucalyptus honey sample } \\
\text { no. 8 }\end{array}$ & - & $383.8^{\mathrm{a}}$ & - \\
& 191.9 & 519.9 & 90.3 \\
& 383.8 & 674.0 & 87.8 \\
& 575.7 & 922.1 & 96.1 \\
& 767.6 & 1039.7 & 90.3 \\
& 959.5 & 1268.1 & 94.4 \\
& & & $\mu^{\mathrm{b}}=91.8 \pm 3.4$ \\
Orange honey sample no. 2 & - & $290.5^{\mathrm{a}}$ & - \\
& 145.3 & 341.2 & 78.3 \\
& 290.5 & 468.3 & 80.6 \\
& 435.8 & 617.3 & 85.0 \\
& 581.0 & 744.3 & 85.4 \\
& 726.3 & 889.7 & 87.5 \\
& - & - & $\mu^{\mathrm{b}}=83.4 \pm 3.8$ \\
\hline
\end{tabular}

${ }^{\mathrm{a}}$ Quantification of hydrolysable tannins in the honey samples

${ }^{\mathrm{b}}$ Average \pm relative standard deviation (RSD) of five determinations

\section{Conclusions}

A new method is presented for determination of hydrolysable tannins in honey samples. The method can be successfully applied for the determination of the analyte in the matrix studied, avoiding possible environmental damage caused by the disposal of solvents, because their use is minimal, compared to other methodologies described in the literature. Advantages of the diffuse reflectance spectroscopy technique include operational simplicity, speed, and low analytical cost. The methodology is environmental friendly and in accordance with the principles of Green Chemistry, with low consumption of reagents and samples, and generates minimal waste during the analyses. Another important feature of the proposed method is that it does not require any elaborate cleanup steps or other sample pretreatments.

Acknowledgments We would like to thank CNPq for the financial support and for a scholarship awarded to T. A. Catelani.

Compliance with Ethical Standards On behalf of all the authors of this original research paper, the author Helena Redigolo Pezza declares that this article does not contain any studies involving human participants or animals performed by any of the authors.

Funding This study was funded by Conselho Nacional de Desenvolvimento Científico e Tecnológico (CNPq), Brasília, Brazil.

Conflict of Interest Helena Redigolo Pezza declares that he has no conflict of interest. Tiago Augusto Catelani declares that he has no conflict of interest. Dayana Borges Bittar declares that he has no conflict of interest. Leonardo Pezza declares that he has no conflict of interest.

Informed consent Not applicable.

\section{References}

Ahmed AYBH, Obbed MS, Wabaidur SM, AlOthman ZA, Al-Shaalan NH (2014) High-performance liquid chromatography analysis of phenolic acid, flavonoid, and phenol contents in various natural Yemeni honeys using multi-walled carbon nanotubes as a solidphase extraction adsorbent. J Agric Food Chem 62:5443-5450

Al-Mamary M, Al-Meeri A, Al-Habori M (2002) Antioxidant activities and total phenolics of different types of honey. Nutr Res 22:10411047

Anastas PT (1999) Green chemistry and the role of analytical methodology development. Crit Rev Anal Chem 29:167-175

Anklam E (1998) A review of the analytical methods to determine the geographical and botanical origin of honey. Food Chem 63:549-562

Bate-Smith EC (1977) Astringent tannins of Acer species. Phytochemistry 16:1421-1426

Bossu CM, Ferreira EC, Chaves FS, Menezes EA, Nogueira ARA (2006) Flow injection system for hydrolysable tannin determination. Microchem J 84:88-92

Campillo N, Viñas P, Férez-Melgarejo G, Ochotorena ML, HernándezCórdoba M (2015) Determination of phenolic acids and hydrolysable tannins in pomegranate fruit and beverages by liquid chromatography with diode array detection and time-of-flight mass spectrometry. Food Anal Methods 8:1315-1325

Chung KT, Wei CI, Johnson MG (1998) Are tannins a double-edged sword in biology and health? Trends Food Sci Tech 9:168-175

Ciappini MC, Stoppani FS (2014) Determination of antioxidant capacity, flavonoids and total phenolic compounds in eucalyptus and clover honeys. J Apic Sci 58:103-111

Codex Alimentarius (2001) Codex standard for honey. http://www. codexalimentarius.org/standards/list-of-standard/honey.pdf. Accessed 3 April 2015

de La Guardia M, Garrigues S (2011) Challenges in green analytical chemistry. Royal Society of Chemistry, Cambridge

Dias NC, Porter MD, Fritz JS (2006) Principles and applications of colorimetric solid-phase extraction with negligible depletion. Anal Chim Acta 558:230-236

Escuredo O, Míguez M, Fernández-González M, Seijo MC (2013) Nutritional value and antioxidant activity of honeys produced in a European Atlantic area. Food Chem 138:851-856

Eterafi-Oskouei T, Najafi M (2013) Traditional and modern uses of natural honey in human diseases: a review. Iran J Basic Med Sci 16: $731-742$

Gheldof N, Wang XH, Engeseth NJ (2002) Identification and quantification of antioxidant components of honeys from various floral sources. J Agric Food Chem 50:5870-5877

Gorjanovic SZ, Alvarez-Suarez JM, Novakovic MM, Pastor FT, Pezo L, Battino M, Suznjevic DZ (2013) Comparative analysis of antioxidant activity of honey of different floral sources using recently developed polarographic and various spectrophotometric assays. J Food Comp Anal 30:13-18

Haslam E (1965) Galloyl esters in the Aceraceae. Phytochemistry 4:495498

Juang LJ, Sheu SJ, Lin TC (2004) Determination of hydrolyzable tannins in the fruit of Terminalia chebula Retz. by high-performance liquid chromatography and capillary electrophoresis. J Sep Sci 27:718724

Keith LH, Gron LU, Young JL (2007) Green analytical methodologies. Chem Rev 107:2695-2708

Khanbabaee K, Ree TV (2001) Tannins: classification and definition. Nat Prod Rep 18:641-649

Kilkuskie RE, Kashiwada Y, Nonaka G, Nishioka I, Bodner AJ, Cheng YC, Lee KH (1992) HIV and reverse transcriptase inhibition by tannins. Bioor Med Chem Lett 2:1529-1534 
Kyraleou M, Pappas C, Voskidi E, Kotseridis Y, Basalekou M, Tarantilis PA, Kallithraka S (2015) Diffuse reflectance Fourier transform infrared spectroscopy for simultaneous quantification of total phenolics and condensed tannins contained in grape seeds. Ind Crop Prod 74:784-791

Long GL, Winefordner JD (1983) Limit of detection: a close look at the IUPAC definition. Anal Chem 55:712A-724A

Mueller-Harvey I (2001) Analysis of hydrolysable tannins. Anim Feed Sci Technol 91:3-20

Nunes CA, Campos DH, Magalhães ECS (2009) Validação de método analítico para determinação do teor de taninos em "Mel Rosado". Rev Bras Farmácia 90:35-38

Pappas C, Kyraleou M, Voskidi E, Kotseridis Y, Taranilis PA, Kallithraka S (2015) Direct and simultaneous quantification of tannin mean degree of polymerization and percentage of galloylation in grape seeds using diffuse reflectance Fourier transform infrared spectroscopy. J Food Sci 80:C298-C306

Romani A, Ieri F, Turchetti B, Mulinacci N, Vincieri FF, Buzzini P (2006) Analysis of condensed and hydrolysable tannins from commercial plant extracts. J Pharm Biomed 41:415-420

Salminen JP, Ossipov V, Haukioja E, Pihlaja K (2001) Seasonal variation in the content of hydrolysable tannins in leaves of Beatula pubescens. Phytochemistry 57:15-22
Scalbert A (1991) Antimicrobial properties of tannin. Phytochemistry 30: 3875-3883

Silva TMS, Santos FP, Evangelista-Rodrigues A, Silva EMS, Silva GS, Novais JS, Santos FAR, Camara CA (2013) Phenolic compounds, melissopalynological, physicochemical analysis and antioxidant activity of jandaíra (Melipona subnitida) honey. J Food Comp Anal 29:10-18

Uthurry CA, Hevia D, Gomez-Cordovez C (2011) Role of honey polyphenols in health. J Apiprod Apimed Sci 3:141-159

Agricultural Marketing Service Fruit and Vegetable Programs Market News Division (2015) National honey report. http://www.ams. usda.gov/mnreports/fvmhoney.pdf. Accessed 2 April 2015

Willis RB, Allen PR (1998) Improved method for measuring hydrolysable tannins using potassium iodate. Analyst 123:435-439

Xie L, Roto AV, Bolling BW (2012) Characterization of ellagitannins, gallotannins, and bound proanthocyanidins from California almond (Prunus dulcis) varieties. J Agric Food Chem 60:2151-2156

Zywicki B, Reemtsma T, Jekel M (2002) Analysis of commercial vegetable tanning agents by reversed-phase liquid chromatographyelectrospray ionization-tandem mass spectrometry and its application to wastewater. J Chromatogr A 970:191-200 